To cite this article: Ulusoy NB. Ortodontik tedavi sonrası oluşan beyaz nokta lezyonlarının rezin infiltrasyon tekniği ile tedavisi: olgu sunumu. Turk J Clin Lab 2019; $10: 272-276$.

\title{
Ortodontik tedavi sonrası oluşan beyaz nokta lezyonlarının rezin infiltrasyon tekniği ile tedavisi: olgu sunumu
}

\author{
Management of post-orthodontic white spot lesions with resin \\ infiltration technique: case report
}

\author{
Nur Burcu ULUSOY*
}

Kırıkkale Üniversitesi Diş Hekimliği Fakültesi, Pedodonti Anabilim Dalı, Kırıkkale/TÜRKiYE

\begin{abstract}
Öz
Beyaz nokta lezyonları, sabit ortodontik braketlerin kullanımı sırasında yetersiz oral hijyen nedeniyle sık görülen önemli bir komplikasyondur. Rezin infiltrasyon (RI) tekniği, rezin materyalin beyaz lezyonun gövdesine infiltre edilmesini sağlayan ve klinik kullanımı yaygınlaşmakta olan bir minimal invaziv restoratif tedavi seçeneğidir. Bu olgu sunumunda, RI tekniğinin klinik uygulama yöntemi ve uzun dönem prognozunun bildirilmesi amaçlanmıştır. On altı yaşında kız hasta, ortodontik tedavi sonrası maksiller ve mandibular dişlerinin labial yüzeylerinde oluşan beyaz nokta lezyonları sebebiyle kliniğimize başvurmuştur. Beyaz lezyonlar, iki seansta RI tekniği (Icon, DMG) ile tedavi edilmiştir. Bu olguda RI tedavisi ile beyaz lezyonların klinik görünümünde belirgin olarak düzelme ve tatmin edici estetik sonuçlar elde edilmiştir. Yirmi dört aylık dönemde bu görünüm değişmeden stabil olarak korunmuş ve lezyonların ilerlemesi engellenmiştir.
\end{abstract}

Anahtar kelimeler: beyaz nokta lezyonu; dental estetik; rezin infiltrasyonu; mine lezyonlarl; ortodontik tedavi

\begin{abstract}
White spot lesions (WSLs) are common post-orthodontic complications that could be attributed to the lack of oral hygiene with fixed orthodontic appliances. Resin infiltration (RI) technique is an increasingly popular, minimally invasive restorative treatment option that involves penetration of a resin into the body of the WSLs. In this case report, the clinical application method, difficulties during application and long-term evidences of RI technique were described. Sixteen-years-old girl referred to our clinic with WSLs on her maxillary and mandibular anterior teeth following orthodontic treatment. Lesions were treated with RI technique (Icon, DMG) in two sessions. The results of our case showed that RI was significantly improved the clinical appearance of WSLs and generated perfect esthetic results. The clinical appearances of the teeth were stable over the twenty four-month period and progression of the lesions was inhibited.
\end{abstract}

Keywords: dental esthetics; enamel lesions; orthodontic treatment; resin infiltration; white spot lesion.

Sorumlu Yazar*: Nur Burcu Ulusoy, Kırıkkale Üniversitesi Diş Hekimliği Fakültesi, Pedodonti Anabilim Dalı, Kırıkkale/TÜRKiYE E-posta: nurburcudutlu@hotmail.com

ORCID: 0000-0002-2707-2819

Gönderim:31.05.2018 Kabul: 09.07.2018

Doi: 10.18663/tjcl.429165 


\section{Giriş}

Beyaz nokta lezyonları, ortodontik tedavi gören hastalarda özellikle sabit aparey kullanımında yaygın görülen bir komplikasyondur. Bu lezyonlar genellikle yetersiz oral hijyen nedeniyle oluşan asidik ortama bağlı olarak, mine yüzeyinde demineralizasyon - remineralizasyon döngüsünün bozulması sonucu meydana gelmektedir. Mine yüzeyi altında demineralize alanlar meydana gelirken, yüzeyde remineralizasyon gerçekleşir ve yüzeydeki kalsiyum, fosfat gibi iyonların yüzey altına difüze olamaması sebebiyle opak görünümlü, pöröz yapıda lezyonlar oluşur [1].

Ortodontik tedavi sonrası beyaz nokta lezyonlarının görülme prevalansı, ölçüm yöntemine, kriterlerine ve önceden mevcut gelişimsel mine defektlerinin ölçüme dahil edilmesine bağlı olarak değişmektedir [2]. Yapılan çalışmalarda hastaların \%37'sinde en az bir yeni beyaz nokta lezyonu görüldüğü bildirilmiştir [3]. Lezyonlar çoğunlukla dişlerin labial yüzeyinin servikal ve orta üçlüsünde görülmekte olup, en fazla etkilenen dişler maksiller ve mandibular birinci molarlar, maksiller lateral, mandibular lateral ve mandibular kaninlerdir [4]. Ortodontik tedavi süresi, beyaz nokta lezyonlarının prevalansını ve şiddetini etkilemekle birlikte, lezyonlar sabit aparey tedavisinin ilk dört haftasında gelişebilmektedir [5]. Diş fırçalama ve tükürük akışı sayesinde beyaz mine lezyonlarında remineralizasyon sağlanabilmektedir; fakat lezyonlar çoğunlukla tamamen kaybolmamaktadır [5].

Günümüzde diş çürüğünün tedavisinde geleneksel, geniş restoratif tedavi protokollerinin yerini, koruyucu bir yaklaşıma, non-invaziv veya minimal invaziv yöntemlere bıraktığı görülmektedir. Modern yaklaşıma göre, çürük riskini değerlendirerek koruyucu tedavi uygulamak ve en erken dönemde çürük teşhisi yaparak en az invaziv yöntemle tedavi etmek esastır [6]. Kavitasyonsuz başlangıç mine çürüklerinin koruyucu tedavisinde topikal florid ve kazein fosfopeptid-amorf kalsiyum fosfat uygulaması gibi non-invaziv yöntemler uygulanabilmektedir; ancak topikal ajanlar kullanılarak tüm lezyon gövdesinde remineralizasyon sağlanamamaktadır [7]. Beyaz nokta lezyonlarında bir tedavi seçeneği olarak uygulanan mikroabrazyon yönteminin ise fazla miktarda mine dokusu kaybına sebep olabileceği bildirilmiştir [7]. Ayrıca geleneksel rezin kompozit restorasyonlar, veneerler ve kronların minenin tamamen uzaklaştırılıp restorasyonun dentine kadar uzanmasını gerektirmesi sebebiyle, genç hastalarda bu restorasyonların uzun dönemde başarılarının sınırlı olduğu bildirilmiştir [1].

Non-invaziv tedavilere seçenek olarak, ilk olarak Robinson ve ark. (1976) tarafından geliştirilen ve son yıllarda modifiye edilerek klinik olarak kullanılmaya başlanan ‘Rezin İnfiltrasyon
(RI)' yöntemi öne çıkmaktadır [8]. Bu tedavi yönteminin amaCl, kavitasyonsuz mine çürüklerinde yüzeydeki porların çürük lezyonunun gövdesi ile beraber tıkanmasının sağlanmasıdır [6]. Bu amaçla yüzeydeki kalın ve hipermineralize mine dokusu asitlenerek uzaklaştırılır ve açığa çıkan demineralize dokudaki mikroporöziteler rezin infiltrant ile doldurulur [9]. Rezin infiltrant olarak, düşük viskozitesi ve yüksek yüzey gerilimi sayesinde mineye çok iyi penetrasyon sağlayan ve ideal bir rezin hidrofilik materyal olan trietilen glikol dimetakrilat (TEGDMA) monomeri kullanılmaktadır [9]. Rezin uygulaması sonucunda mine ve poröz yapılar arasındaki ışığın kırılma katsayısı farkı azalmaktadır ve lezyon çevresindeki sağlam dokulara benzer translüsensi ve renkte izlenmektedir [10].

Yapılan çalışmalarda RI'un ortodontik tedavi sonrası oluşan beyaz nokta lezyonlarının yanı sıra hipoplazik defektler ve florozis vakalarında da uygulanabileceği bildirilmiştir [6].

Bu olgu sunumunda, üst ve alt anterior dişlerde ortodontik tedavi sonrası oluşan beyaz nokta lezyonlarının RI yöntemi ile tedavisi ve iki yıllık takip sonuçlarının bildirilmesi amaçlanmıştır.

\section{Olgu}

14 yaşında kız hasta, 2015 yılında ön dişlerinin estetik olmayan görünümü nedeniyle Kırıkkale Üniversitesi Diş Hekimliği Fakültesi Pedodonti Anabilim Dalına başvurmuştur. Hastadan alınan anamnezde, herhangi bir sistemik hastalığı olmadığı ve ortodontik tedavisinin bir hafta önce sona erdiği öğrenilmiştir. Yapılan intraoral muayenede, maksiller ve mandibular keser, kanin ve birinci premolar dişlerin labial yüzeylerinde debonding sonrası braketlerin sınırlarını takip eden beyaz nokta lezyonları tespit edilmiştir (Şekil 1). Ayrıca servikal bölgelerde, yüzeyel doku kaybı olmayan, kireç beyazı veya sarı renkte başlangıç mine lezyonları gözlenmiş olup, tüm lezyonların Uluslararası Çürük Teşhis ve Değerlendirme Sistemine (ICDAS II) göre Kod 2 grubuna dahil olduğu belirlenmiştir. Radyografik muayenede ise maksiller sağ lateral, mandibular sağ santral ve lateral dişlerde proksimal yüzeylerde dentin çürüğü (ICDAS II Kod 5) tespit edilmiştir.

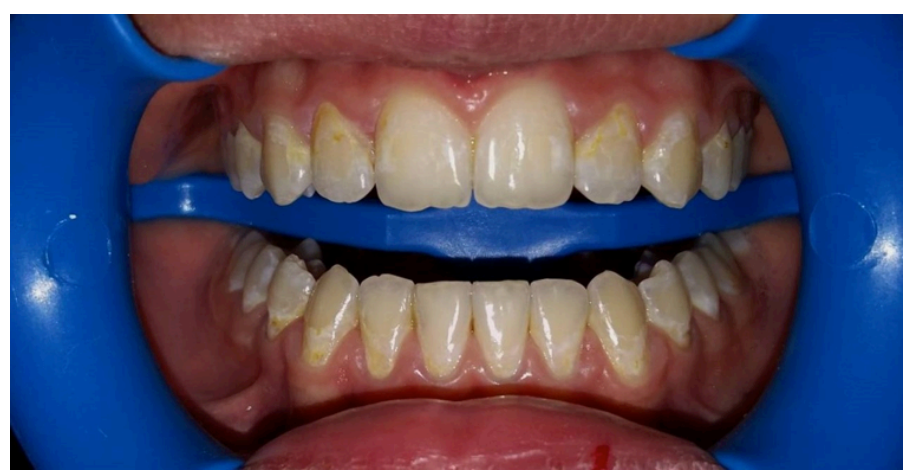

Şekil 1: Hastanın başlangıç intraoral fotoğrafı 
Öncelikle, hasta ve velisi bilgilendirilmiş ve yazılı olarak imzaIı onam alınmıştır. Tedavi planlamasına göre, iki seans periodontal tedavinin ardından, kazein fosfopeptit-amorf kalsiyum fosfat jel preparatı (GC Tooth Mousse, Tokyo, Japonya) kullanımına başlanmıştır. Bir ay takip sonrasında beyaz nokta lezyonlarında gerileme sağlanamadığından, hastaya RI tedavisinin uygulanmasına karar verilmiştir. Dentin çürükleri bulunan dişlerin ise kompozit materyal ile restoratif tedavisi planlanmıştır. Tedavide ilk olarak diş yüzeyleri polisaj patı ve periodontal lastik kullanılarak temizlenmiş ve maksiller keser, kanin ve birinci premolar dişler rubber-dam ile izole edilmiştir (Şekil 2a). İzole edilen mine yüzeylerine \%15'lik hidroklorik asit jel (Icon-Etch, DMG, Hamburg, Almanya) 2 dakika süreyle uygulanmış ve 30 saniye boyunca yıkanmıştır (Şekil 2b). Ardından yüzeyler basınçlı havayla kurutulmuş ve etanol içerikli materyal (Icon-Dry, DMG, Hamburg, Almanya) yüzeylere uygulanarak 30 saniye beklenmiştir (Şekil 2c). Böylece yüzeydeki su tabakasının tamamen uzaklaşması sağlanmıştır. Yüzeydeki opasitelerin renginin düzeltilerek optimize edilebilmesi için bu işlemler iki kez yinelenmiştir. Dişlerde istenilen yüzey görüntüsü elde edildikten sonra, Rezin İnfiltrant (Icon-Infiltrant, DMG, Hamburg, Almanya) yüzeylere 3 dakika boyunca fırçası yardımıyla tatbik edilmiştir. Daha sonra infiltrantın hava kurutması ile yüzeye homojen biçimde yayılması sağlanmış ve diş ipi yardımıyla interproksimal alanlar temizlenmiştir. Yüzeylerin 40 saniye süreyle ışıkla polimerizasyonu sonrasında, rezin infiltrant 1 dakika boyunca tekrar uygulanmış ve polimerize edilmiştir. Son olarak, gren boyutu kalından inceye doğru azalan diskler, silikon lastikler ve arayüz zımparaları (Super-Snap Rainbow Technique Kit Shofu, Japonya) kullanılarak mine yüzeylerinin polisajı yapılmıştır.

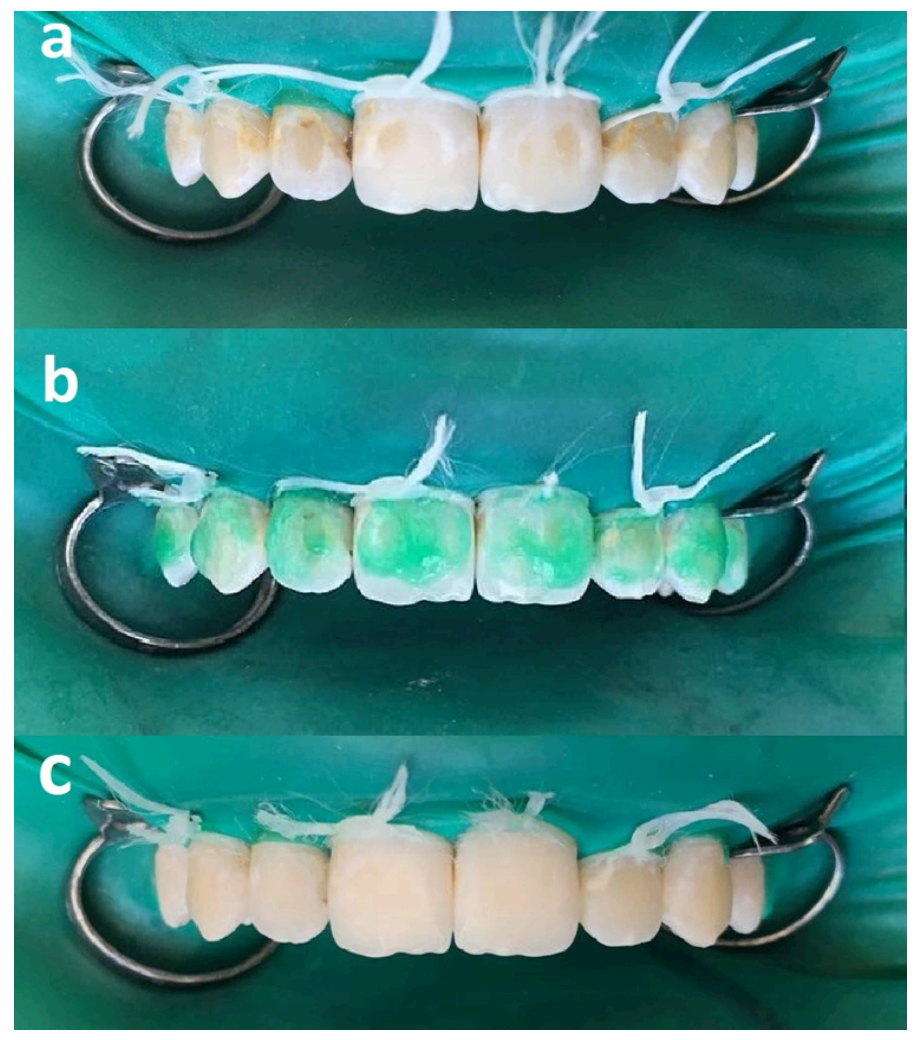

Şekil 2: Maksiller dişlere uygulanan tedavi basamakları (a) Rubberdam izolasyonu (b) Icon-Etch uygulaması (c) Icon-Dry uygulaması
Tedavinin ikinci seansında, mandibular sol lateral ile mandibular sağ ve sol kanin ve birinci premolar dişlere, rubber-dam izolasyonu altında maksiller dişlere benzer şekilde RI tedavi basamakları uygulanmıştır (Şekil 3). Son olarak, proksimal yüzeylerinde dentin çürüğü bulunan maksiller sağ lateral, mandibular sağ santral ve lateral dişlerin kompozit rezin (Singlebond Universal Bond, Filtek Ultimate Universal Restorative, 3M ESPE, $A B D$ ) ile restorasyonu yapılmış ve tedaviler tamamlanmıştır (Şekil 4). İki yıl boyunca düzenli aralıklarla takip edilen dişlerde 12 ay sonra hiçbir klinik veya radyografik değişim görülmezken, 24 ay sonunda yapılan tüm restorasyonların bozulmadan korunduğu ve renginde değiş̧im olmadığı izlenmiş̧tir.

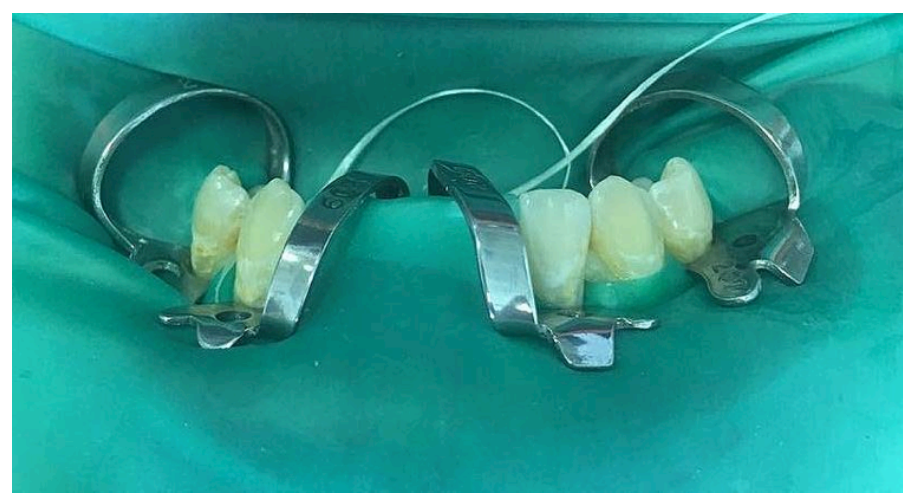

Şekil 3: Mandibular dişlerin tedavi öncesi alınan fotoğrafı

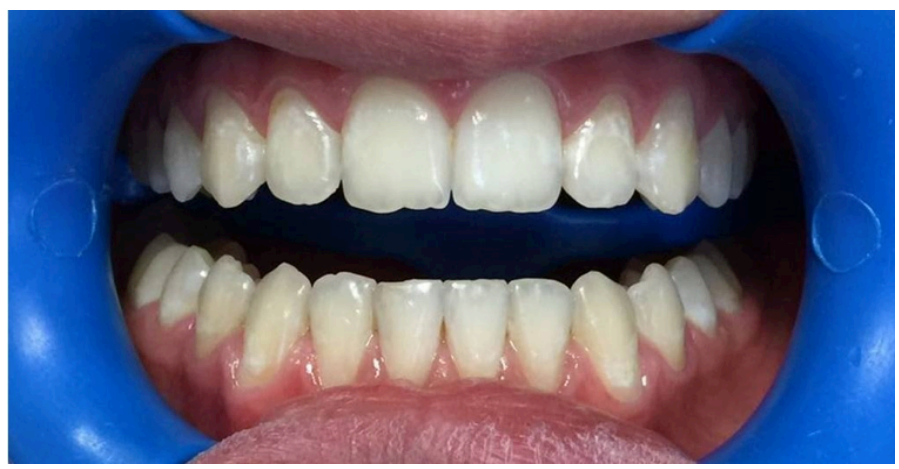

Şekil 4: Hastanın tedavisi sonrası intraoral fotoğrafı

\section{Tartışma}

Ortodontik tedavi gören hastalarda oral hijyenin yetersizliği nedeniyle, dişlerin mine tabakasında beyaz nokta lezyonlarına sıklıkla rastlanmaktadır [2]. Bu durum estetik görünümü olumsuz yönde etkilemekle birlikte, demineralizasyonun ilerlemesi halinde kavitasyonlu mine/dentin çürüklerinin oluşumuna neden olabilmektedir.

Ortodontik tedavi sonrasında görülen beyaz nokta lezyonlarına çoğunlukla genç hastalarda rastlanmakta olup, tedavisinde topikal ajanlar yetersiz kalmakta, protetik tedaviler ise önerilmemektedir [1]. Başlangıç çürüklerine bağlı beyaz lezyonların 
tedavisinde önerilen diğer yöntemler ise beyazlatma ve mikroabrazyondur. Karbamid peroksit veya hidrojen peroksit içeren ajanların diş yüzeyine uygulandığı beyazlatma tedavisi ile daha estetik sonuçlar elde edilmeye çalışılsa da, bu yöntemin demineralize diş yapısının güçlendirilmesinde etkili olmadığı belirtilmiştir [11]. Mikroabrazyon yönteminde demineralize mine dokusunun uzaklaştırılması amacıyla, \% 18'lik hidroklorik asit aşındırıcı materyal ile karıştırılıp beyaz lezyon üzerine uygulanmaktadır [12]. Ancak bu yöntemin yalnızca yüzeyel mine tabakasında etkinlik sağlayabildiği, başlangıç çürüklerinin (>0.2 mm) uzaklaştırılması için yeterli olmadığı bildirilmiştir $[11,12]$. Bunlara ek olarak okluzal yüzeyde bulunan başlangıç mine lezyonlarında kullanılan konvansiyonel pit ve fissür örtücüler, yüzeyel bir koruyucu tabaka şeklinde izlenmekte olup lezyonun gövdesine diffüze olamamaktadır [6].

Bu yöntemlere alternatif olarak geliştirilen RI yöntemi, mine yüzeyindeki porların lezyon gövdesiyle beraber tıkanmasını sağlar ve daha kuvvetli bir bağlanma elde edilir [6, 13]. Böylece bir difüzyon bariyeri oluşturularak demineralize mine yapısı güçlendirilir. Yapılan bir çalışmada, çürük lezyonlarında RI etkinliğinin mine-dentin birleşimine kadar uzandığı bildirilmiştir [13]. Bu sayede lezyonun karyojenik ortamda bile daha yavaş ilerlediği öne sürülmüştür [13].

Yapılan bir in vitro çalışmada, beyaz nokta lezyonlarının rengindeki opasitenin giderilmesinde, tükürük etkisi ile remineralizasyon, günlük \% 0.05 'lik florid solüsyonu uygulaması, haftalık \% 2'lik florid jel uygulaması ve RI tedavisinin etkinlikleri karşılaştırılmıştır [14]. Çalışmada, dişlerdeki opak rengin maskelenmesinde RI tedavisinin diğer tüm yöntemlerden daha başarılı olduğu bildirilmiştir. Ayrıca tedavi edilen dişlerin yeniden asit atağına maruz kalması sonrası en az renk değişimi, RI grubundaki dişlerde tespit edilmiştir [14].

Yetkiner ve ark. (2014) yaptıkları in vitro çalışmada, beyaz nokta lezyonlarının tedavisinde RI, mikroabrazyon ve floridin etkinliğini karşılaştırmıştır. Buna göre; RI ve mikroabrazyon uygulanmış dişlerde opak görünümün kaybolduğu; fakat yalnızca RI uygulanan dişlerde rengin stabil olarak kaldığı tespit edilmiştir [15]. Benzer olarak Senestraro ve ark. (2013) yaptıkları in vivo çalışmada, post-ortodontik beyaz nokta lezyonlarının RI tedavisinde 2, 6, ve 12 aylık takip sonucunda renk değişikliği görülmediğini bildirmiştir [1]. Bu olgu sunumunda, infiltre edilmiş lezyonlar 24 ay süreyle gözlemlenerek, RI sonucu elde edilen rengin stabil kaldığı izlenmiştir.

Yapılan bir diğer çalışmada, debonding sonrasında tespit edi- len beyaz nokta lezyonlarının farklı şiddetlerde izlenebileceği, bu nedenle yapılan RI tedavisi sonrasında farklı sonuçlar ortaya çıkabileceği bildirilmiştir [16]. Bu çalışmada genel olarak tüm dişlerde estetik görünümde iyileşme sağlanmış; ancak çok şiddetli opasitelerde lezyon gövdesinin tamamının rezin ile doldurulamaması sebebiyle opak görünümün tam olarak kaybolmadığı belirtilmiştir [16]. Bununla beraber hafif ve orta şiddetli beyaz lezyonlarda ICDAS II skorunun 2'den, 1 veya 0’a kadar gerilediği görülmüştür [16]. Beyaz lezyonların infiltrasyonunda, estetik görünümün yanı sıra lezyonun aktivitesindeki değişim de göz önünde bulundurulmalıdır. Benzer olarak, sunduğumuz bu olguda çok şiddetli lezyonların tamamen kaybolmadığı, ancak 24 aylık takipte çürük ilerlemesinin durdurulduğu gözlenmiştir. Sonuç olarak RI tedavisi ile beyaz nokta lezyonlarının klinik görünümünde belirgin olarak düzelme ve tatmin edici estetik sonuçlar elde edilmiştir.

\section{Çıkar Çatışması / Finansal Destek Beyanı}

Çalışmayı maddi olarak destekleyen kişi/kuruluş yoktur ve yazarların herhangi bir çıkar dayalı ilişkisi yoktur.

\section{Kaynaklar}

1. Senestraro SV, Crowe JJ, Wang M, et al. Minimally invasive resin infiltration of arrested white-spot lesions: a randomized clinical trial. J Am Dent Assoc 2013; 144: 997-1005.

2. Höchli D, Hersberger-Zurfluh M, Papageorgiou SN, Eliades T. Interventions for orthodontically induced white spot lesions: a systematic review and meta-analysis. Eur J Orthod 2017; 39: 122-33.

3. Willmot DR, Brook AH. The incidence of post-orthodontic demineralized enamel lesions in an orthodontic clinic. J Dent Res 1999; 78: 1049.

4. Mizrahi E. Surface distribution of enamel opacities following orthodontic treatment. Am J Orthod Dentofacial Orthop 1983; 84: 323-31.

5. Ogaard B, Rolla J, Arends J. Orthodontic appliances and enamel demineralization. Part 1. Lesion development. Am J Orthod Dentofacial Orthop 1998; 94: 68-73.

6. Doméjean S, Ducamp R, Léger S, Holmgren C. Resin infiltration of non-cavitated caries lesions: a systematic review. Med Princ Pract $2015 ; 24: 216-21$

7. Akin M, Basciftci FA. Can white-spot lesions be treated effectively? Angle Orthod 2012; 82: 770-75.

8. Robinson C, Hallsworth AS, Weatherell JA, Künzel W. Arrest and control of carious lesions: a study based on preliminary experiments with resorcinol-formaldehyde resin. J Dent Res 1976; 55: 812-18. 
9. Meyer-Lueckel H, Paris S. Progression of artificial enamel caries lesions after infiltration with experimental light curing resins. Caries Res 2008; 42: 117-24.

10. Paris S, Meyer-Lueckel H. Masking of labial enamel white spot lesions by resin infiltration-A clinical report. Quintessence Int 2009; 40: 713-18.

11. Kalender B. Başlangıç çürük lezyonlarının tedavisi. Turkiye Klinikleri J Restor Dent-Special Topics 2017; 3: 58-65.

12. Sundfeld RH, Croll TP, Briso AF, de Alexandre, RS, Neto DS. Considerations about enamel microabrasion after 18 years. Am J Dent 2007; 20: 67
13. Paris $\mathrm{S}$, Meyer-Lueckel $\mathrm{H}$. Infiltrants inhibit progression of natural caries lesions in vitro. J Dent Res 2010; 89: 1276-80.

14. Torres CRG, Borges AB, Torres LMS, Gomes IS, de Oliveira RS. Effect of caries infiltration technique and fluoride therapy on the colour masking of white spot lesions. J Dent 2011; 39: 202-07.

15. Yetkiner E, Wegehaupt F, Wiegand A, Attin R, Attin T. Colour improvement and stability of white spot lesions following infiltration, micro-abrasion, or fluoride treatments in vitro. Eur J Orthod 2014; 36: 595-602.

16. Neuhaus KW, Graf M, Lussi A, Katsaros C. Late infiltration of postorthodontic white-spot lesions. J Orofac Orthop 2010; 71: 442-47. 